\title{
Assessment of inter-city transport of particulate matter in the Beijing-Tianjin-Hebei region
}

\author{
Xing Chang ${ }^{1}$, Shuxiao Wang ${ }^{1,2}$, Bin Zhao ${ }^{3}$, Siyi Cai ${ }^{1}$, and Jiming Hao ${ }^{1,2}$ \\ ${ }^{1}$ State Key Joint Laboratory of Environment Simulation and Pollution Control, School of Environment, Tsinghua University, \\ Beijing 100084, China \\ ${ }^{2}$ State Environmental Protection Key Laboratory of Sources and Control of Air Pollution Complex, Beijing 100084, China \\ ${ }^{3}$ Joint Institute for Regional Earth System Science and Engineering and Department of Atmospheric and Oceanic Sciences, \\ University of California, Los Angeles, CA 90095, USA
}

Correspondence: Shuxiao Wang (shxwang@tsinghua.edu.cn) and Bin Zhao (zhaob1206@ucla.edu)

Received: 10 October 2017 - Discussion started: 13 November 2017

Revised: 8 March 2018 - Accepted: 11 March 2018 - Published: 10 April 2018

\begin{abstract}
The regional transport of particulate matter with diameter less than $2.5 \mu \mathrm{m}\left(\mathrm{PM}_{2.5}\right)$ plays an important role in the air pollution of the Beijing-Tianjin-Hebei (BTH) region in China. However, previous studies on regional transport of $\mathrm{PM}_{2.5}$ mainly aim at province level, which is insufficient for the development of an optimal joint $\mathrm{PM}_{2.5}$ control strategy. In this study, we calculate $\mathrm{PM}_{2.5}$ inflows and outflows through the administrative boundaries of three major cities in the BTH region, i.e., Beijing, Tianjin and Shijiazhuang, using the WRF (Weather Research and Forecasting model)-CMAQ (Community Multiscale Air Quality) modeling system. The monthly average inflow fluxes indicate the major directions of $\mathrm{PM}_{2.5}$ transport. For Beijing, the $\mathrm{PM}_{2.5}$ inflow fluxes from Zhangjiakou (in the northwest) and Baoding (in the southwest) constitute $57 \%$ of the total in winter, and Langfang (in the southeast) and Baoding constitute $73 \%$ in summer. Based on the net $\mathrm{PM}_{2.5}$ fluxes and their vertical distributions, we find there are three major transport pathways in the BTH region: the northwest-southeast pathway in winter (at all levels below $1000 \mathrm{~m}$ ), the northwestsoutheast pathway in summer (at all levels below $1000 \mathrm{~m}$ ), and the southwest-northeast pathway in both winter and in summer (mainly at 300-1000 m). In winter, even if surface wind speeds are low, the transport at above $300 \mathrm{~m}$ can still be strong. Among the three pathways, the southwest-northeast happens along with $\mathrm{PM}_{2.5}$ concentrations 30 and $55 \%$ higher than the monthly average in winter and summer, respectively. Analysis of two heavy pollution episodes in January and July in Beijing show a much (8-16 times) stronger transport than
\end{abstract}

the monthly average, emphasizing the joint air pollution control of the cities located on the transport pathways, especially during heavy pollution episodes.

\section{Introduction}

The Beijing-Tianjin-Hebei (BTH) region, one of the most developed regions in China, is suffering from severe pollution involving particulate matter with diameter less than $2.5 \mu \mathrm{m}\left(\mathrm{PM}_{2.5}\right)$. According to the monitoring data from the China National Environmental Monitoring Center (http:// www.cnemc.cn/, last access: 10 January 2018), the average $\mathrm{PM}_{2.5}$ concentrations of the BTH region in 2013, 2014 and 2015 were 106,93 and $77 \mu \mathrm{g} \mathrm{m}^{-3}$, respectively, which far exceeded the $35 \mu \mathrm{g} \mathrm{m}^{-3}$ standard in China. The high $\mathrm{PM}_{2.5}$ concentrations have adverse impacts on visibility (P. Zhao et al., 2011) as well as human health (Zhang et al., 2013), and thus may cause a large economic loss (Mu and Zhang, 2013). Reducing the $\mathrm{PM}_{2.5}$ concentration in the $\mathrm{BTH}$ region is therefore critical.

Emissions from one city can substantially affect the $\mathrm{PM}_{2.5}$ pollution in another city under particular meteorological conditions via the transport process. For example, some studies have shown that emissions from outside Beijing can contribute $28-70 \%$ of the ambient $\mathrm{PM}_{2.5}$ concentration in Beijing (An et al., 2007; Streets et al., 2007; BJEPB, 2015; Z. Wang et al., 2014). A number of approaches have consequently been applied to evaluate the inter-city transport 
Table 1. Summary of the emissions of major pollutants in Beijing, Tianjin and 11 prefecture-level cities in Hebei in 2012.

\begin{tabular}{lrrrrrrrr}
\hline Emissions (kt yr & $\left.\mathrm{NO}_{x}\right)$ & $\mathrm{SO}_{2}$ & $\mathrm{PM}_{2.5}$ & $\mathrm{PM}_{10}$ & $\mathrm{BC}$ & $\mathrm{OC}$ & $\mathrm{NMVOCs}$ & $\mathrm{NH}_{3}^{\mathrm{a}}$ \\
\hline Beijing & 202 & 120 & 75 & 177 & 9 & 9 & 381 & 52 \\
Tianjin & 392 & 287 & 113 & 151 & 17 & 26 & 287 & 45 \\
Hebei & 1620 & 1079 & 875 & 1172 & 141 & 221 & 1346 & 628 \\
Shijiazhuang & 270 & 198 & 149 & 203 & 23 & 33 & 230 & 87 \\
Chengde & 84 & 45 & 37 & 49 & 6 & 10 & 56 & 34 \\
Zhangjiakou & 112 & 52 & 41 & 54 & 7 & 11 & 56 & 35 \\
Qinhuangdao & 71 & 39 & 30 & 40 & 5 & 8 & 51 & 22 \\
Tangshan & 266 & 145 & 100 & 135 & 15 & 24 & 181 & 68 \\
Langfang & 79 & 71 & 63 & 86 & 10 & 14 & 100 & 35 \\
Baoding & 158 & 123 & 118 & 155 & 20 & 33 & 202 & 89 \\
Cangzhou & 149 & 121 & 109 & 148 & 17 & 25 & 164 & 67 \\
Hengshui & 79 & 66 & 62 & 84 & 10 & 15 & 92 & 50 \\
Xingtai & 140 & 105 & 77 & 102 & 13 & 21 & 113 & 60 \\
Handan & 213 & 115 & 89 & 117 & 15 & 26 & 148 & 82 \\
\hline
\end{tabular}

of $\mathrm{PM}_{2.5}$ and its effect on local air quality. Backward trajectory models, such as the HYSPLIT model (Stein et al., 2015), are one of the most commonly used methods. This method provides the most probable transport trajectory of the air mass before it arrives at a target location; however, it cannot quantify the inter-city transport of $\mathrm{PM}_{2.5}$. Another commonly used method is the sensitivity analysis based on Euler 3-D models, such as CMAQ (Community Multiscale Air Quality model), which is undertaken by calculating the change in concentration due to a change in emissions. This method includes the brute force method (e.g., Wang et al., 2015), the decoupled direct method (DDM, Itahashi et al., 2012), and the response surface model (RSM, Zhao et al., 2015). These methods are all based on a chemical transport model, so that the physical and chemical processes can both be well considered. However, the sensitivity of $\mathrm{PM}_{2.5}$ concentration in the target city to emissions from the source city is not necessarily the same as the contribution of transport process, due to the non-linear relationships between emissions and concentrations (Kwok et al., 2015).

Based on the simulated meteorology field and air pollutant concentrations, the inter-city transport of $\mathrm{PM}_{2.5}$ can be simply expressed by the $\mathrm{PM}_{2.5}$ flux through city boundaries. Compared to the preceding methods, the flux approach can give direct and quantitative assessment of the transport of pollutants without a heavy calculation burden. This approach has been widely applied to assess the large scale transport of air pollutants, such as inter-continent transports (Berge and Jakobsen, 1998; In et al., 2007). There have also been studies that evaluated pollutant transport on a regional scale (Jenner and Abiodun, 2013; Wang et al., 2009); some of which focused on the BTH region (An et al., 2012; Wang et al., 2010). In these studies, the boundaries for flux calculations are at the province level. However, in China, the air pollution control strategy is formulated and implemented at the city level. Moreover, most previous studies regarding $\mathrm{PM}_{2.5}$ transports in the BTH region have focused on Beijing. In recent years, however, under the policy of "integrating development of BTH region", the air quality in Tianjin and the cities in Hebei Province are being increasingly emphasized. Therefore, a systematic assessment of the $\mathrm{PM}_{2.5}$ flux at the city level in the BTH region is needed.

In this study, we select Beijing, Tianjin and Shijiazhuang as target cities, and calculate the inter-city $\mathrm{PM}_{2.5}$ transport fluxes through the administrative boundaries between the target cities and the neighboring prefecture-level cities, based on the WRF (Weather Research and Forecasting model) CMAQ modeling system. The $\mathrm{PM}_{2.5}$ transport pathways in the $\mathrm{BTH}$ region are identified based on the $\mathrm{PM}_{2.5}$ transport flux results.

\section{Methodology}

\subsection{Emission inventory}

A multiscale emission inventory is used in this study. For the region outside mainland China, we use the MIX emission inventory (Li et al., 2017) of the year 2010. For the Chinese mainland other than the BTH region, we adopt a gridded emission inventory of 2012 developed in our previous study (Cai et al., 2017). For the BTH region, we develop a bottom-up emission inventory of 2012. A unit-based approach is used for power plants, iron and steel plants and cement plants (Zhao et al., 2008); an emission factor approach is used for other sectors (Fu et al., 2013; Zhao et al., 2013b; Wang et al., 2014). In particular, emissions in Beijing are updated from the bottom-up inventory developed by Tsinghua University and Beijing Municipal Research Institute of Environmental Protection (BJEPB, 2010; B. Zhao et al., 2011). The emissions of major pollutants in each city are shown in Table 1. Methods for the biogenic emissions, the volatile organic compound (VOC) speciation and the spatial and tem- 


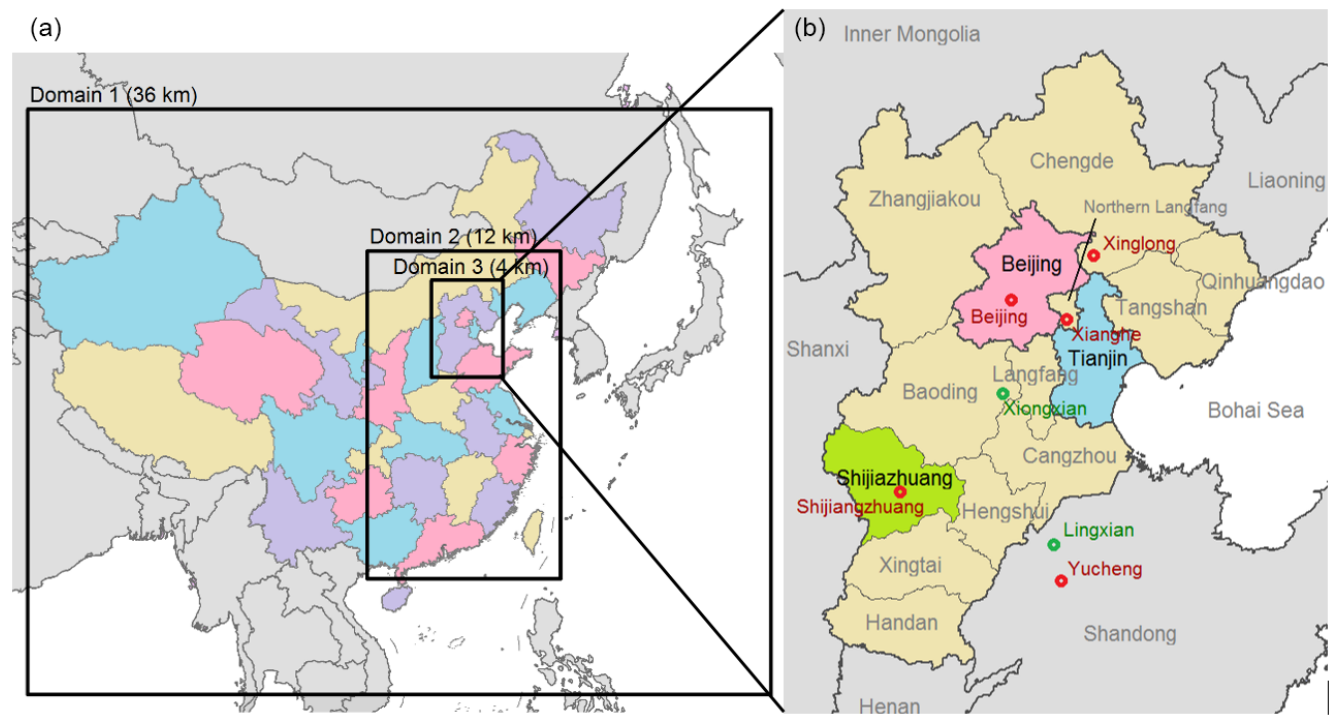

Figure 1. The simulation domains used in this study (a) and the map of the Beijing-Tianjin-Hebei region (b). The highlighted cities are the target cities for flux calculation. The red circles show the sites with $\mathrm{PM}_{2.5}$ observations. The two sites with green circles have observations of $\mathrm{PM}_{2.5}$ chemical components in 2013.

poral allocation of emissions are consistent with our previous study (Zhao et al., 2013a). The spatial distributions of emissions are shown in Fig. S1 (see the Supplement).

\subsection{WRF-CMAQ model configuration}

We establish a one-way, triple nesting domain in the WRFCMAQ model to simulate the meteorology and air pollutant fields, as shown in Fig. 1. Domain 1 covers mainland China and part of East Asia and Southeast Asia at a grid resolution of $36 \mathrm{~km} \times 36 \mathrm{~km}$; Domain 2 covers eastern China at a grid resolution of $12 \mathrm{~km} \times 12 \mathrm{~km}$; Domain 3 covers the BTH region at a grid resolution of $4 \mathrm{~km} \times 4 \mathrm{~km}$, which is the target area of this study. The simulation periods are January and July 2012 representing the winter and summer time, respectively.

For the WRF (version 3.7) model, $23 \sigma$ levels are selected for the vertical grid structure. The top layer pressure is 100 mbar at approximately $15 \mathrm{~km}$. The National Center for Environmental Prediction (NCEP)'s Final Operational Global Analysis data with a horizontal resolution of $1^{\circ} \times 1^{\circ}$ at every $6 \mathrm{~h}$ are used to generate the first guess field. The NCEP's Automated Data Processing (ADP) data are used in the objective analysis scheme. The major physics options are the Kain-Fritsch cumulus scheme, the Pleim-Xiu land surface model, the ACM2 planetary boundary layer (PBL) scheme, the Morrison double-moment cloud microphysics scheme and the rapid radiative transfer model (RRTM) longwave and shortwave radiation scheme. The MeteorologyChemistry Interface Processor (MCIP) version 3.3 is applied to convert the WRF output data to the format required by CMAQ.
We use CMAQv5.0.2 to simulate the air quality field. The CMAQ model is configured with the AERO6 aerosol module and the CB-05 gas-phase chemical mechanism. The default profile is used to generate the boundary condition of the first domain, and the simulation results of the outer domains provide the boundary conditions for the inner domains. The simulation begins five days ahead of each month to minimize the impact of initial condition.

The model predicted meteorology and $\mathrm{PM}_{2.5}$ concentrations are compared with observation data. The results are shown in the Supplement. The simulations agree well with observations. Most of the indices are within the benchmarks suggested by Emery et al. (2001). We evaluate simulated $\mathrm{PM}_{2.5}$ concentrations against observations at five sites located in Domain 3, i.e., Beijing, Shijiazhuang, Xianghe, Xinglong and Yucheng (see Fig. 1), as shown in Table 2. The time series of simulated and observed $\mathrm{PM}_{2.5}$ concentrations are shown in Fig. 2. It can be seen that the variation trends of $\mathrm{PM}_{2.5}$ are well reproduced in both January and July for all five sites. The average $\mathrm{PM}_{2.5}$ concentrations are slightly underestimated in January, while the underestimation is larger in July at most sites, especially in Beijing and Xinglong. However, the MFB and MFE indices in January and July for the domain all fall inside the "criteria" benchmark value suggested by Boylan and Russell (2006). To understand the reason for the underestimation, it is necessary to evaluate the simulation results for major components of $\mathrm{PM}_{2.5}$. Given that we have no observations for $\mathrm{PM}_{2.5}$ components in 2012 in the BTH region, we additionally simulate the air quality in July and August in 2013, and compare it with the $\mathrm{PM}_{2.5}$ component observations at several sites (see details in the Supplement). Generally, the underestimation of total $\mathrm{PM}_{2.5}$ 
Table 2. Comparison of the simulated and observed $\mathrm{PM}_{2.5}$ concentrations at five sites.

\begin{tabular}{|c|c|c|c|c|c|c|c|}
\hline $\begin{array}{l}\text { Indices } \\
\text { Unit }\end{array}$ & & $\begin{array}{r}\text { Mean OBS } \\
\mu \mathrm{g} \mathrm{m}^{-3}\end{array}$ & $\begin{array}{r}\text { Mean } \text { SIM }^{\mathrm{a}} \\
\mu \mathrm{g} \mathrm{m}^{-3}\end{array}$ & $\begin{array}{r}\mathrm{NMB} \\
\%\end{array}$ & $\begin{array}{r}\mathrm{NME} \\
\%\end{array}$ & $\begin{array}{r}\text { MFB } \\
\%\end{array}$ & $\begin{array}{r}\text { MFE } \\
\%\end{array}$ \\
\hline \multirow{5}{*}{ January 2012} & Beijing & 86.0 & 65.2 & -24.2 & 32.2 & \multirow{5}{*}{-19.6} & \multirow{5}{*}{19.6} \\
\hline & Shijiazhuang & 193.9 & 170.8 & -11.9 & 45.3 & & \\
\hline & Xianghe & 132.3 & 85.6 & -35.3 & 44.5 & & \\
\hline & Xinglong & 39.4 & 38.6 & -2.0 & 42.7 & & \\
\hline & Yucheng & 140.9 & 124.1 & -11.9 & 31.2 & & \\
\hline \multirow{5}{*}{ July 2012} & Beijing & 68.2 & 35.6 & -47.8 & 49.5 & \multirow{5}{*}{-35.1} & \multirow{5}{*}{40.2} \\
\hline & Shijiazhuang & 70.3 & 79.8 & +13.6 & 37.6 & & \\
\hline & Xianghe & 61.3 & 47.2 & -23.0 & 35.6 & & \\
\hline & Xinglong & 48.9 & 24.6 & -49.6 & 53.8 & & \\
\hline & Yucheng & 77.3 & 55.2 & -28.6 & 39.6 & & \\
\hline \multirow{2}{*}{\multicolumn{2}{|c|}{$\begin{array}{l}\text { "Criteria" benchmark } \\
\text { "Goal" benchmark }\end{array}$}} & - & - & - & - & $\leq \pm 60$ & $\leq 75$ \\
\hline & & - & - & - & - & $\leq \pm 30$ & $\leq 50$ \\
\hline
\end{tabular}

${ }^{a}$ Average of the days when only observations are available. ${ }^{b}$ Benchmarks are suggested by Boylan and Russell (2006).

in the summer time mainly comes from the underestimation of organic carbon (OC) and sulfate. The default CMAQ tends to underestimate secondary organic aerosol to a large extent, especially in summer when photochemical reactions are active, which is a common problem of most widely used chemical transport models (Simon and Bhave, 2012; Heald et al., 2005; Zhao et al., 2016). The lack of aqueous oxidation of $\mathrm{SO}_{2}$ by $\mathrm{NO}_{2}$ (Wang et al., 2016), and $\mathrm{SO}_{2}$ oxidation at dust surface (Fu et al., 2016) may partly account for the underestimation of sulfate. The underestimation of sulfate also partly explains the overestimation of nitrate. Moreover, the biases of major $\mathrm{PM}_{2.5}$ components in the current study fall in a similar range with other studies in the BTH region (Wang et al., 2015, 2011; L. T. Wang et al., 2014a; Zhao et al., 2017; Liu et al., 2016) (see details in the Supplement). In conclusion, the biases of simulated meteorological field and $\mathrm{PM}_{2.5}$ concentrations fall in a reasonable range. The modeling results can be used for further studies.

\section{$2.3 \quad$ PM $_{2.5}$ flux calculation}

The $\mathrm{PM}_{2.5}$ flux in this study stands for the mass of $\mathrm{PM}_{2.5}$ that flows through a particular vertical surface in a particular period of time. The vertical surface extends from the ground to a specific vertical level along the boundary of two regions (Fig. 3a). However, the model can only provide a three-dimensional discrete wind field and $\mathrm{PM}_{2.5}$ concentration field. Therefore, the vertical surface through which the flux is calculated is discretized to several vertical grid cells, as is illustrated in Fig. $3 \mathrm{~b}$ and detailed in the next paragraph. In this case, the expression of $\mathrm{PM}_{2.5}$ flux can be written as

Flux $=\sum_{i=1}^{h} \sum_{l} L H_{i} c \boldsymbol{v} \cdot \boldsymbol{n}$, where $l$ is the boundary line of two regions; $h$ is the top layer; $L$ is the grid width; $H_{i}$ is the height between layer $i$ and $i-1$; $c$ is the concentration of $\mathrm{PM}_{2.5}$ at the vertical grid cell; $\boldsymbol{v}$ is the wind vector; and $\boldsymbol{n}$ is the normal vector of the vertical grid cell. The variables in the expression can be obtained from the output of the models. We choose the 9th layer above the ground (about $1000 \mathrm{~m}$ ) as the top layer, because most of the $\mathrm{PM}_{2.5}$ transport between regions happens inside the boundary layer (Shi et al., 2008). Even though the transport could happen above the boundary layer, the influence of such transport on the near-ground concentrations is less important because the vertical mixing above the boundary layer is weaker.

Beijing and Tianjin are two of the most important and developed megacities in the BTH region. Shijiazhuang is the capital city, and also one of the most developed and polluted cities in Hebei province. Therefore, we chose these three cities as the target cities for flux calculation. In order to accurately distinguish the transport from different adjacent cities and to understand the net $\mathrm{PM}_{2.5}$ inflow of a city as a whole, all the administrative boundaries between the target city and the adjacent cities are chosen as the boundary lines. The boundary lines are separated to different segments by neighbor cities, and the fluxes are calculated separately for each segment. The locations of the three target cities and their neighbors are shown in Fig. 1. Note that there is a small area surrounded by Beijing and Tianjin that belongs to the city of Langfang, so the boundaries between Beijing and Tianjin, Beijing and Langfang and Tianjin and Langfang are each separated into two segments. To distinguish them, we add the relative location of the boundary to the neighboring city's name, like "Beijing (N)" and "Beijing (S)".

The flux varies every now and then, depending on the wind direction. The polluted air mass may flow in, affect the local air quality and subsequently flow out in a short period of 

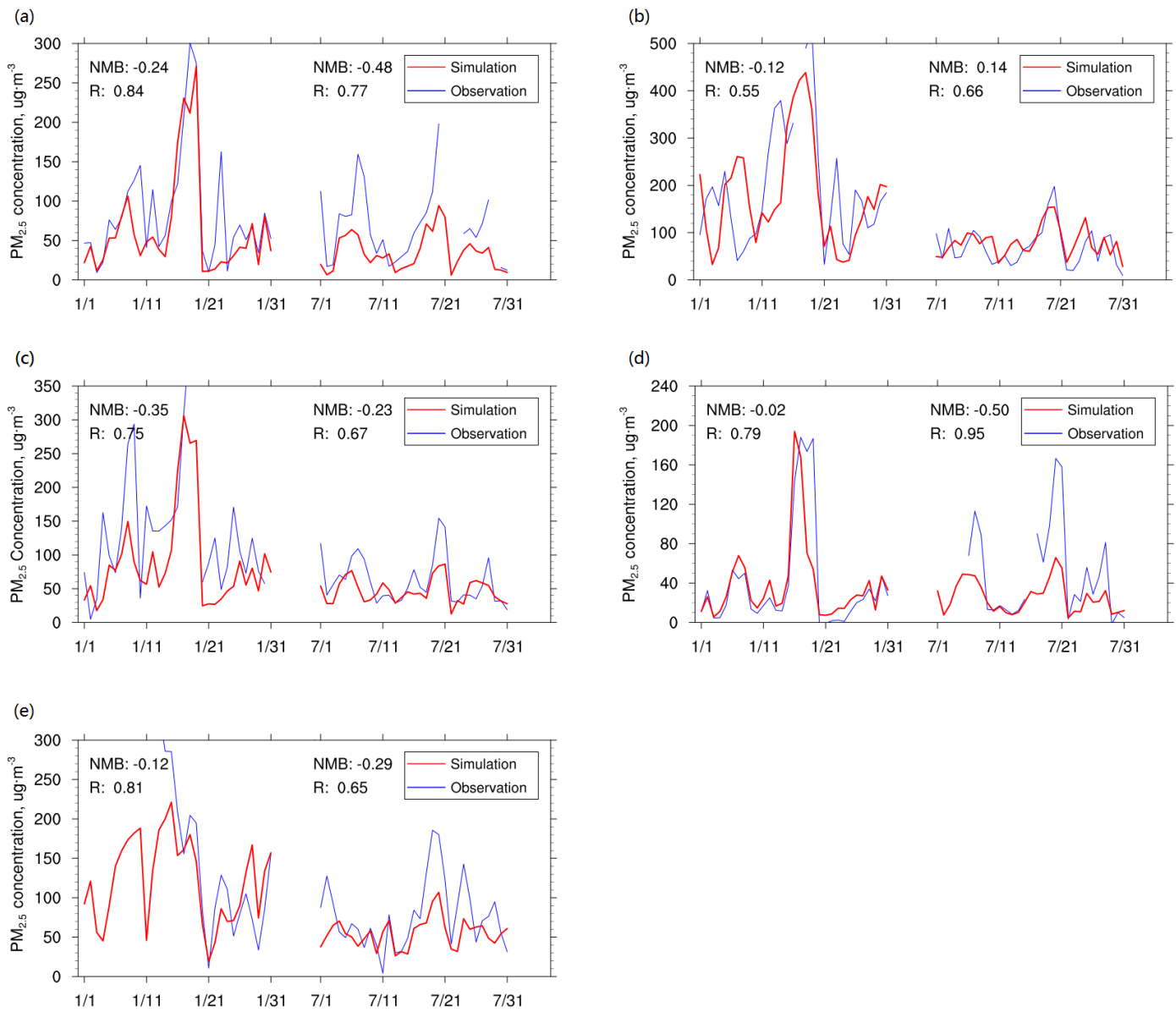

Figure 2. Time series of the simulated and observed $\mathrm{PM}_{2.5}$ concentrations in (a) Beijing, (b) Shijiazhuang, (c) Xianghe, (d) Xinglong and (e) Yucheng.

time, so that the fluxes may offset each other during the integration. To characterize the intensity of interactions between two regions as well as the general impact of $\mathrm{PM}_{2.5}$ transport, three indices are therefore chosen in regard to the flux calculation, these are the inflow flux, the outflow flux and the net flux.

\section{Results and discussion}

\subsection{Characteristics of the inter-city $\mathbf{P M}_{2.5}$ transport in January}

The monthly inflow, outflow and net fluxes through each boundary segment of the three target cities are shown in Fig. 4, from which we get an overview of the transport over a relatively long period of time. We treat the fluxes as positive if $\mathrm{PM}_{2.5}$ flows into the target cities, and negative if $\mathrm{PM}_{2.5}$ flows out of the target cities. The positive total net fluxes in Beijing and Shijiazhuang consequently reveal that the $\mathrm{PM}_{2.5}$ inflows of these two cities generally exceed the outflows, and that these cities act as a "sink" of $\mathrm{PM}_{2.5}$. This is possibly due to the unique terrain of Beijing and Shijiazhuang. These two cities are both half surrounded by western and northern mountains, while major emissions of $\mathrm{PM}_{2.5}$ lie to the south and east. Consequently, pollutants are easily trapped in the bulging part of the plain if there is a weak wind from the south or the east. The trapped pollutants are either scavenged by wet deposition without flowing out, or diluted by strong vertical convection due to the strong northwestern wind brought by the cold front and thus flow out of the boundary layer. Tianjin, in contrast, behaves as a "source" of $\mathrm{PM}_{2.5}$ flux. Furthermore, a probe into the detailed inflow, outflow and net fluxes through each boundary segment of the three cities may help us understand the extent to which the cities interact with their neighbors. For Beijing, in winter, the inflow fluxes mainly come from Zhangjiakou (in the northwest) and Baoding (in the southwest), and the outflows primarily go to Chengde (in the northeast) and Langfang (in the southeast). For Tianjin, Langfang (in the northwest) and Tangshan (in the northeast) contribute most of the inflow fluxes, and the Bohai Sea (in the southeast) and Tangshan again receive the major outflow fluxes. Shijiazhuang acts dif- 
(a)

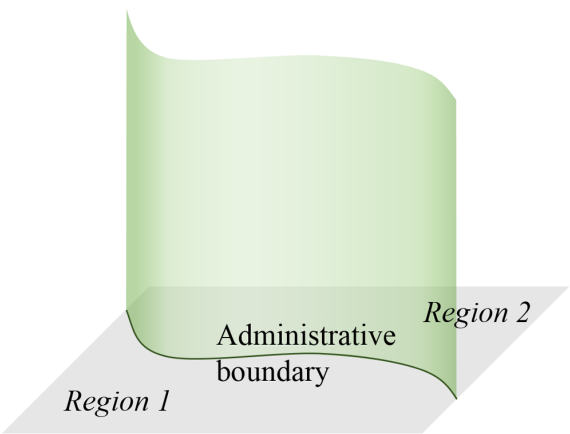

(b)

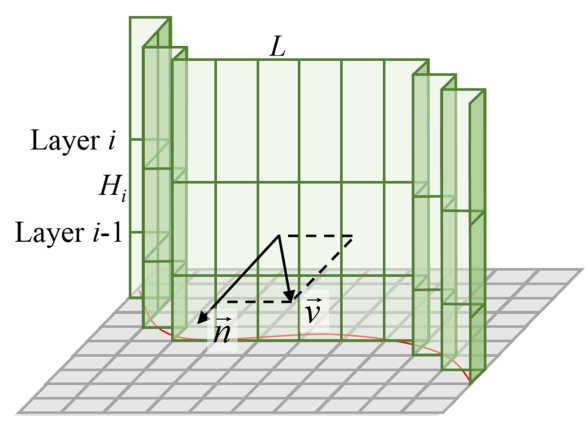

Figure 3. An example of the vertical surface for flux calculation (a) before discretization, and (b) after discretization.

ferently from both Beijing and Tianjin. The inflow and outflow fluxes through all the four boundary segments are considerably strong, with Xingtai (in the south) and Baoding (in the northeast) contributing relatively more to inflow and outflow fluxes, respectively.

$\mathrm{PM}_{2.5}$ fluxes may vary with height. We calculate the vertical distribution of net flux through each boundary segment to determine at what level the transport mainly occurs. The results are shown in Fig. 5a, c and e. The fluxes of each vertical layer in the CMAQ model are shown separately, and the approximate elevation of each layer is marked on the left. Generally, the total flow intensity is stronger at higher levels for all three cities, while the major contributor varies with layers. If we add up the net fluxes through all boundary segments (Figure 5: shown by the narrow bars with an envelope line), we can see that the "sink" behavior of Beijing mainly stems from the total net fluxes at 400 to $600 \mathrm{~m}$ where the contribution from Baoding (in the southwest) exhibits a rapid increase with height. Similarly, the total net flux for Tianjin shows a peak value near $600 \mathrm{~m}$ where Tangshan (in the northeast) receives much more outflow than it does near the ground. Total net flux for Shijiazhuang shows a peak value near $400 \mathrm{~m}$ where Hengshui (in the east) and Xingtai (in the south) display dominant contributions.

In order to better understand the transport characteristics of the BTH region, we display the net flux results on a map, using arrows to represent the net flux direction and intensity. The result for January is shown in Fig. 6a. Bigger arrows represent larger fluxes, and white and black arrows denote fluxes at the lower (layer 1-5 in the model, from the ground to about $310 \mathrm{~m}$ ) and upper (layer 6-9 in the model, from about $310 \mathrm{~m}$ to about $1000 \mathrm{~m}$ ) layers, respectively. From the map we can identify two key $\mathrm{PM}_{2.5}$ transport pathways in the BTH region in January: the northwest-southeast pathway (Zhangjiakou $\rightarrow$ Beijing $\rightarrow$ Langfang $\rightarrow$ Tianjin $\rightarrow$ The Bohai Sea) and the southwest-northeast pathway (Xingtai $\rightarrow$ Shijiazhuang $\rightarrow$ Baoding $\rightarrow$ Beijing $\rightarrow$ Chengde). The former is related to the prevailing wind brought by the winter monsoon in the
$\mathrm{BTH}$ region, and happens at both lower and higher layers. The latter occurs mainly at higher layers.

According to the Ekman spiral, wind speed is much higher at the upper level of the boundary layer (Holton and Hakim, 2012), meaning that pollutants can travel longer distances during their lifetime. Assuming that the emission height of each city is similar, we believe that a $\mathrm{PM}_{2.5}$ inflow at higher altitude most probably originates from a farther source. From this point of view, the $\mathrm{PM}_{2.5}$ flow of the southwest-northeast pathway at higher levels may consist of relatively long-range transport. In winter time, the southwest wind field usually occurs after the passage of a cold high pressure system, when the wind speed is low and the sky is clear. Such air conditions trap less upward infrared radiation at night, which helps enhance the air stability, or even causes temperature inversion. Moreover, the southwest wind also brings moisture, leading to the formation of fog, which may enhance the aqueous reaction to form more particles. Therefore, southwest wind is usually accompanied by pollution. The southwest-northeast transport pathway should consequently be intensely considered during the winter time in the BTH region. The northwest wind, in contrast, usually comes during the passage of a cold high pressure system, with a relatively high wind speed at both lower and higher levels bringing dry, cold and clean air from non-polluted areas. The large fluxes from northwest are more likely due to the strong winds rather than high $\mathrm{PM}_{2.5}$ levels.

\subsection{Characteristics of inter-city $\mathbf{P M}_{2.5}$ transport in July}

We conduct the same calculation in July to investigate the transport characteristics in summer. The monthly average inflow, outflow and net fluxes are shown in Fig. 4. Similarly to January, total net fluxes are positive (more inflow than outflow) for Beijing and Shijiazhuang, and negative (more outflow than inflow) for Tianjin, although the magnitude is much higher than that in January. In detail, the inflow fluxes for Beijing mainly come from Langfang (in the southeast) and Baoding (in the southwest), and the outflow fluxes mainly go to Chengde (in the northeast) and Zhangjiakou (in the north- 
west). For Tianjin, Bohai Sea (in the east) and Tangshan (in the northeast) contribute a large part of the inflow, and Langfang (in the northwest) and Tangshan receive most of the outflow fluxes. The transport directions for Beijing and Tianjin in July are quite different from those in January. However, for Shijiazhuang, all four directions (Shanxi, Baoding, Hengshui and Xingtai) still contribute a comparable amount of inflow and outflow fluxes, where inflows from Xingtai (in the south) and Hengshui (in the east) are slightly larger.

Figure $5 \mathrm{~b}, \mathrm{~d}$ and $\mathrm{f}$ display the vertical distributions of monthly average net fluxes with respect to the three cities in July. For Beijing, the total net fluxes are positive at all levels, which are different from those observed in January. The major contributors, Baoding and Langfang, show different behaviors; net flux from Baoding is nearly zero near the ground, but increases rapidly with height, while the net flux from Langfang (including both Langfang $(\mathrm{N})$ and Langfang (S)) is significant at all levels, and is largest at medium height. These phenomena are tied to the wind speed and direction at different heights in the BTH region in summer. The dominant wind direction near the ground is from the southeast. Within the boundary layer, the wind rotates clockwise and becomes stronger at higher levels according to Ekman spiral (Holton and Hakim, 2012). Langfang and Baoding are located to the southeast and southwest of Beijing, respectively. The increase in wind speed and the rotation of wind direction could therefore constantly enhance the $\mathrm{PM}_{2.5}$ transported from the southwest. For the transport from southeast, however, the increase in wind speed enhances it but the rotation of wind direction weakens it, causing a local maximum in middle layers. For Tianjin, the overall outflow mainly occurs at levels below $600 \mathrm{~m}$, where the outflow flux primarily goes to Langfang. The inflow flux is dominated by the Bohai Sea at all heights, indicating a cross-sea transport from Shandong or other areas. The vertical distribution of net fluxes for Shijiazhuang is quite similar to that in January, except that Shanxi does not contribute a considerable amount of inflow flux during this particular period.

The general transport characteristics in the BTH region for the summer period are represented by arrows on the map in Fig. 6b. Compared with the transport characteristics in winter, the transport at lower layers becomes stronger. We also note two major transport pathways in the BTH region in July: the southwest-northeast pathway (Xingtai $\rightarrow$ Shijiazhuang $\rightarrow$ Baoding $\rightarrow$ Beijing $\rightarrow$ Chengde), and the southeastnorthwest pathway (Bohai $\rightarrow$ Tianjin $\rightarrow$ Langfang $\rightarrow$ Beijing $\rightarrow$ Zhangjiakou, and Hengshui $\rightarrow$ Shijiazhuang). The latter pathway, which is caused by the summer monsoon, is significant at both lower and upper layers. The pathway from southwest to northeast in comparison is only obvious at upper layers. Considering that in summer the vertical mixing is stronger, although the southwest-northeast pathway is only active at higher levels, the transport may still affect the nearground concentration remarkably.
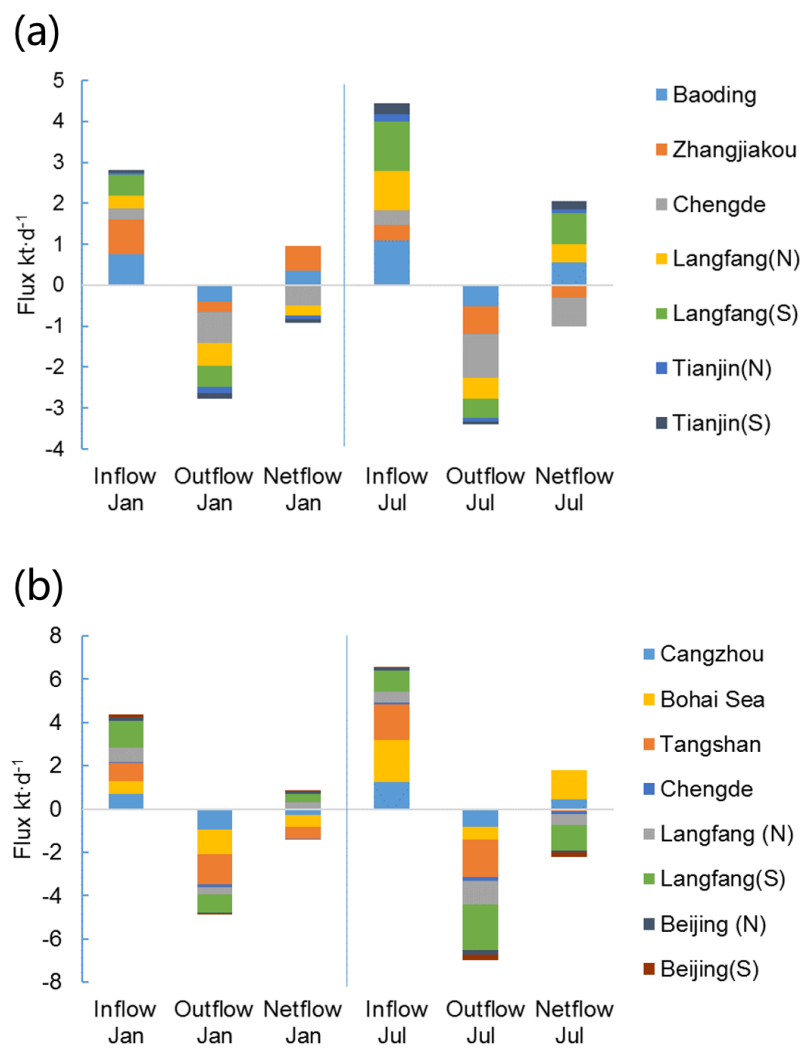

(c)

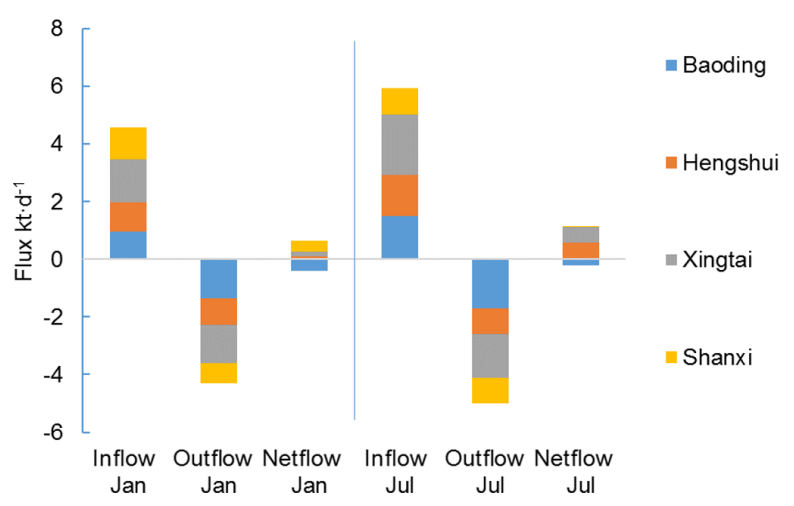

Figure 4. The inflow, outflow and net fluxes in January and July for (a) Beijing, (b) Tianjin and (c) Shijiazhuang.

If we combine the transport characteristics in winter and summer, we can see that, aside from the opposite transport pathways brought by the monsoon in different seasons, there is a steady transport pathway from southwest to northeast in the BTH region regardless of the season. This pathway has also been found in various other studies. Wu et al. (2017) analyzed the regional persistent haze events in the BTH region during 1980-2013, and found that southwestern wind field at $925 \mathrm{hPa}(\sim 800 \mathrm{~m})$ is a typical meteorological condition. Backward trajectory studies by Zhao et al. (2017) also found 
(a) Beijing, Jan

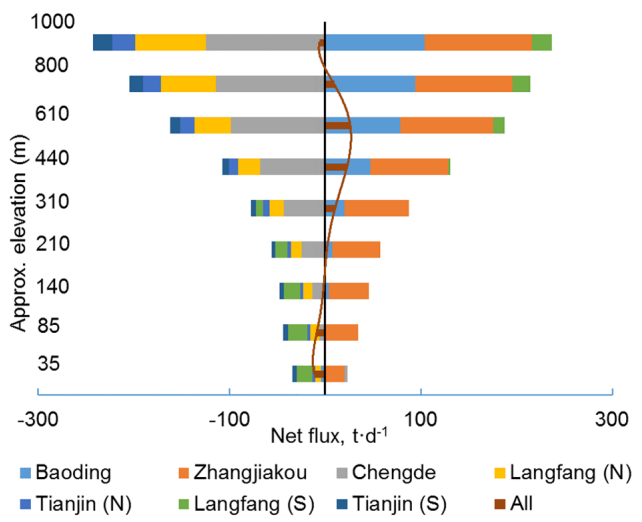

(c) Tianjin, Jan

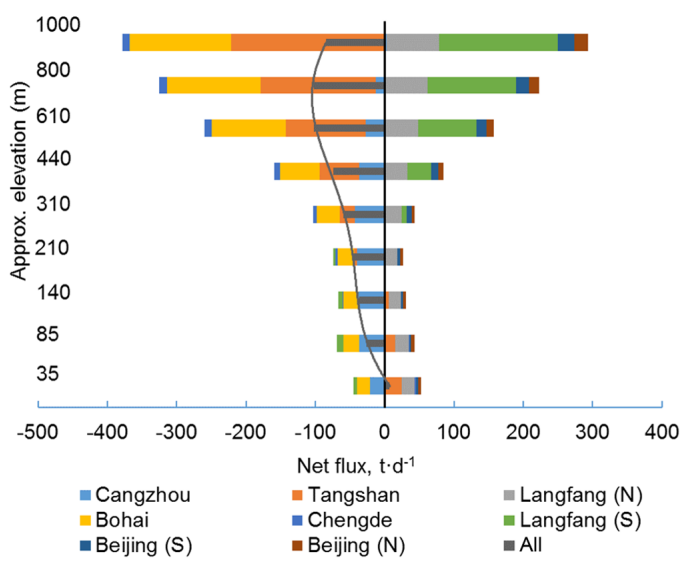

(e) Shijiazhuang, Jan

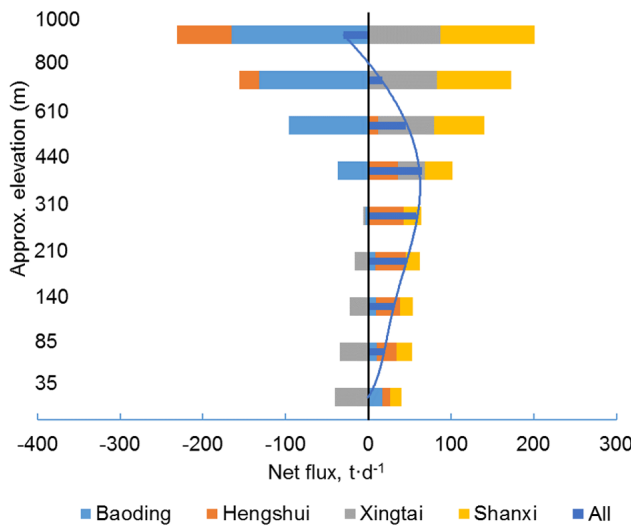

(b) Beijing, Jul

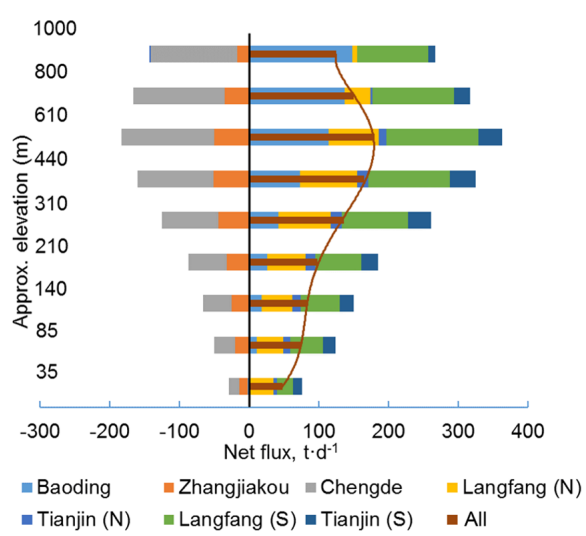

(d) Tianjin, Jul

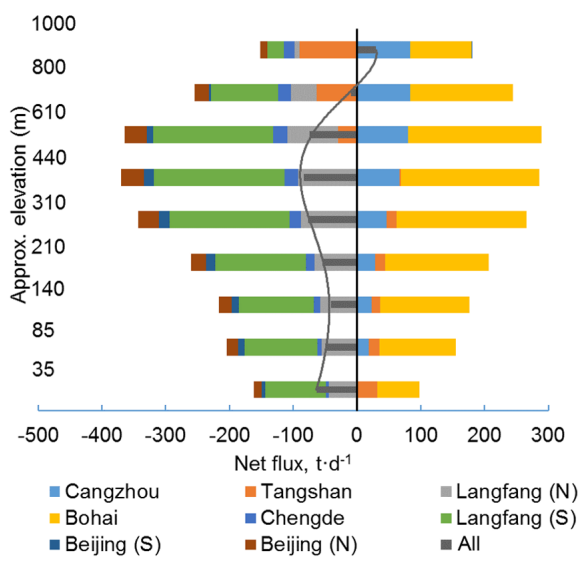

(f) Shijiazhuang, Jul

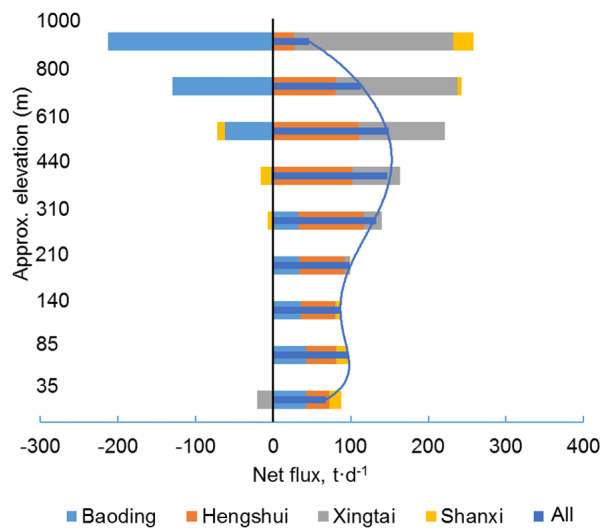

Figure 5. Vertical distribution of net fluxes in January (a, c, e) and July (b, d, f) for (a-b) Beijing, (c-d) Tianjin and (e-f) Shijiazhuang.

a southerly transport pathway during pollution periods in the BTH region. Therefore, the southwest-northeast pathway is indeed important in this particular area.

To better understand how the wind and $\mathrm{PM}_{2.5}$ concentration affect the transport fluxes, we calculate the frequency of wind directions and the corresponding wind speed and $\mathrm{PM}_{2.5}$ concentration, and plot them as "wind rose" plots. We show the plots for Beijing in Fig. 7 as an example. The plots for the other two cities can be found in the Supplement.

In January, the dominant wind directions near the ground ranges from northwest to northeast. The north-northeast wind has the highest frequency, while the northwest wind 
(a)

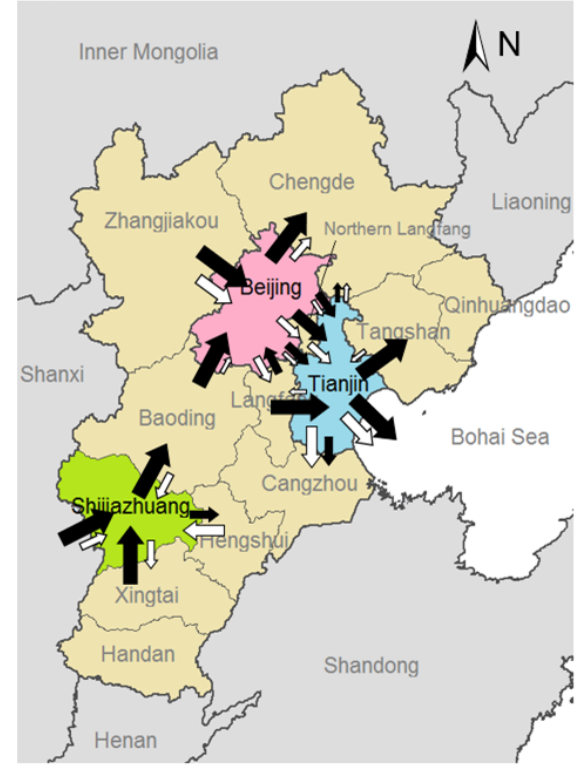

(b)

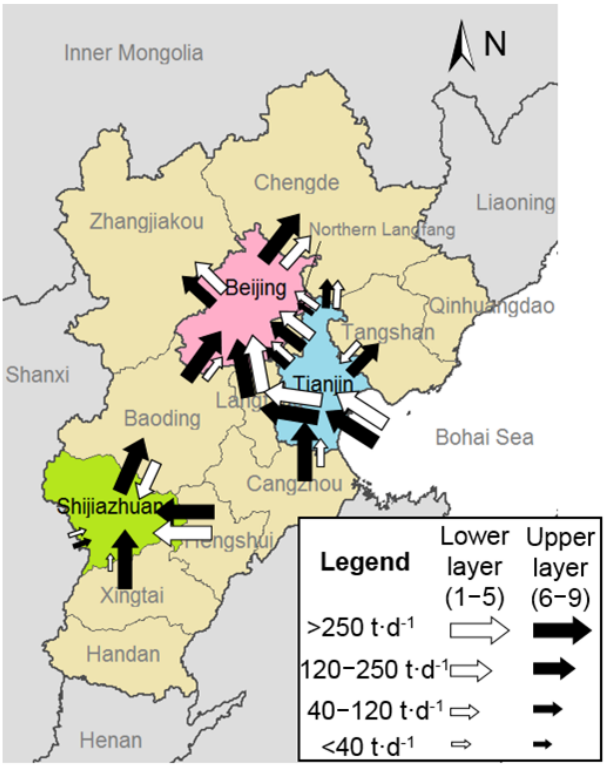

Figure 6. The transport fluxes through each boundary segment of the three target cities in January (a) and July (b). The size of the arrows represents the amount of the fluxes, while white and black arrows denote fluxes at the lower (layer 1-5 in the model, from the ground to about $310 \mathrm{~m}$ ) and upper (layer 6-9 in the model, from about $310 \mathrm{~m}$ to about $1000 \mathrm{~m}$ ) layers, respectively.

has the highest wind speed (Fig. 7a). The dominant northern winds reflect the winter monsoon. Although the $\mathrm{PM}_{2.5}$ concentrations carried via the northern winds are relatively low because of the low emission rate in that particular direction(Fig. 7b), the high frequency and wind speed also cause an overall strong transport from the northwest to the southeast. Wind directions and the corresponding concentrations are quite different in the upper layers (Fig. 7c, d). The prevalent northern wind remains (though the dominant directions shift slightly from north-northeast to northwest), and the frequency of southwestern winds is much higher than that at lower layers. Moreover, the $\mathrm{PM}_{2.5}$ concentrations that come with southwestern winds are much higher than concentrations from other directions. The strong emissions in southern Hebei (which lies southwest of Beijing), especially the elevated source, may be responsible for the high concentration from the southwest. Therefore, in January, the dominant northwestern winds account for the northwest-southeast pathway at both lower and upper layers, while the large emissions from the southwest are a major contributor to the southwest-northeast pathway at upper layers.

In July, the dominant winds at the lower layer are from the southeast, reflecting the summer monsoon (Fig. 7e), and coincidentally the highest $\mathrm{PM}_{2.5}$ concentrations are also associated with southeastern winds (Fig. 7f). Emissions from Tianjin, Langfang and Tangshan may influence Beijing via the southeastern winds. The emissions and the wind direction both contribute to the southeast-northwest pathway at the lower layers. The high frequency winds shift clockwise to more southerly directions at the upper layers in July, as is shown in Fig. $7 \mathrm{~g}$, and the southwest and the southeast winds are both important. Moreover, the wind directions with the high concentrations also shift to both southwest and the southeast directions (Fig. 7h). Therefore, in July, the dominant southeastern winds and emissions from the southeast caused the southeast-northwest pathway at both the upper and lower layers. The southwest-northeast pathway is an integrated effect of the southern winds and the emissions, which is different from that in January.

These monthly transport characteristics could bring us inspiration on how the joint control of different cities should be applied. The transport pathway at lower layers suggests that we should primarily control nearby low-level emission sources, while the pathway at upper layers calls for control over a larger region in the upstream direction.

\subsection{The daily characteristics of $\mathbf{P M}_{2.5}$ transport in Beijing}

In addition to the monthly characteristics of $\mathrm{PM}_{2.5}$ transports discussed in Sect. 3.2, we analyze the daily characteristics in this sector, taking Beijing as an example. Firstly, since different $\mathrm{PM}_{2.5}$ concentrations may be caused by different meteorological conditions, and may also result in different transport flux characteristics on different days, we initially calculate the $\mathrm{PM}_{2.5}$ flux during different pollution levels (Fig. 8). We sort the daily data into six groups in January and five groups in July. The separating points are chosen to be near the $30,55,75,85$ and 95 percentiles in January, and the 30, 
(a)

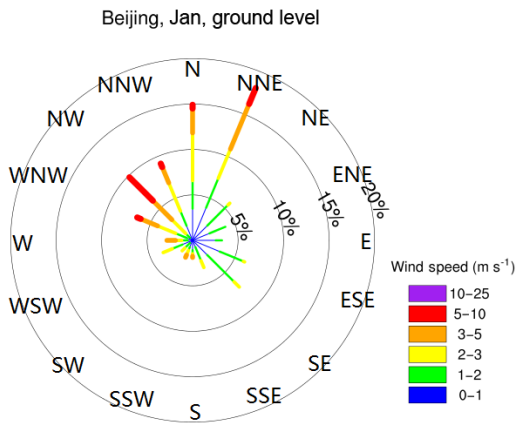

(c)

Beijing, Jan, 450-600 m

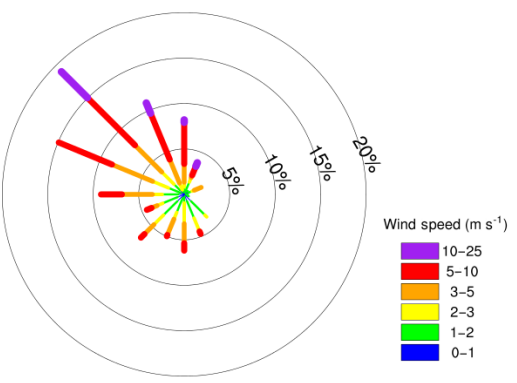

(e)

Beijing, Jul, ground level

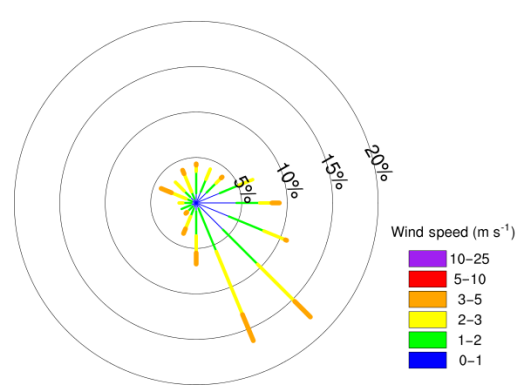

(g)

Beijing, Jul, 450-600 m

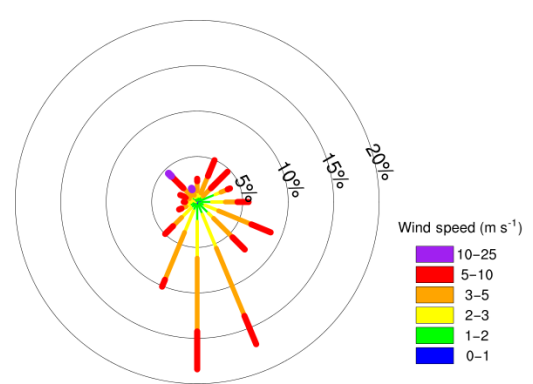

(b)

Beijing, Jan, ground level

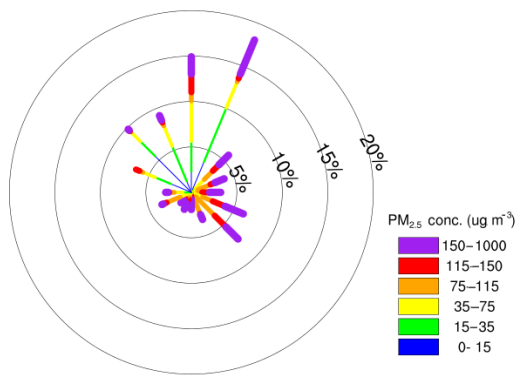

(d)

Beijing, Jan, 450-600 m

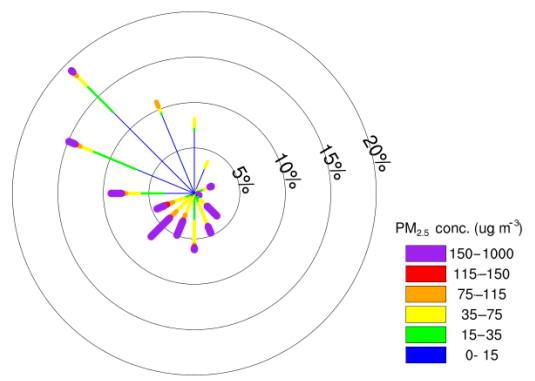

(f)

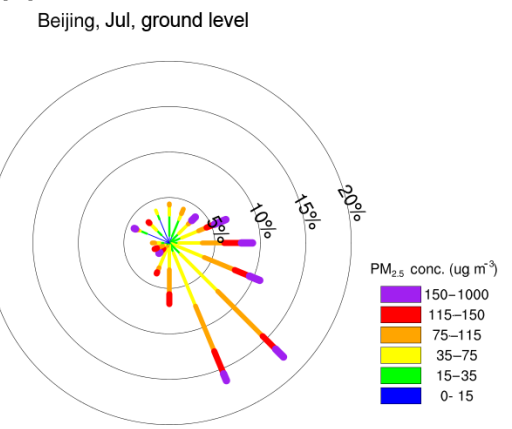

(h)

Beijing, Jul, 450-600 m

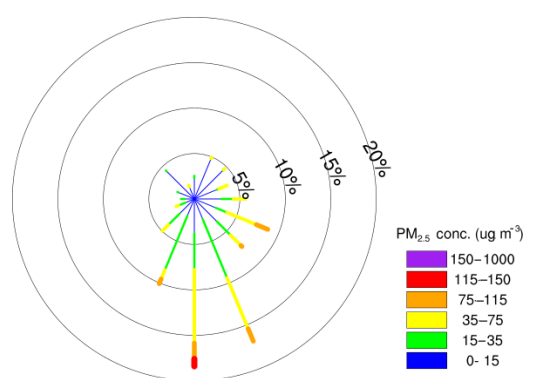

Figure 7. Wind rose plots showing the frequency of wind speed (a, $\mathbf{c}, \mathbf{e}, \mathbf{g})$ and $\mathrm{PM}_{2.5}$ concentration $(\mathbf{b}, \mathbf{d}, \mathbf{f}, \mathbf{h})$ at different wind directions for Beijing. The ground level and the 7th level (about 450-600 $\mathrm{m}$ ) in the model are chosen as the representation of lower levels and upper levels. The percentages denote the frequency. 
(a)
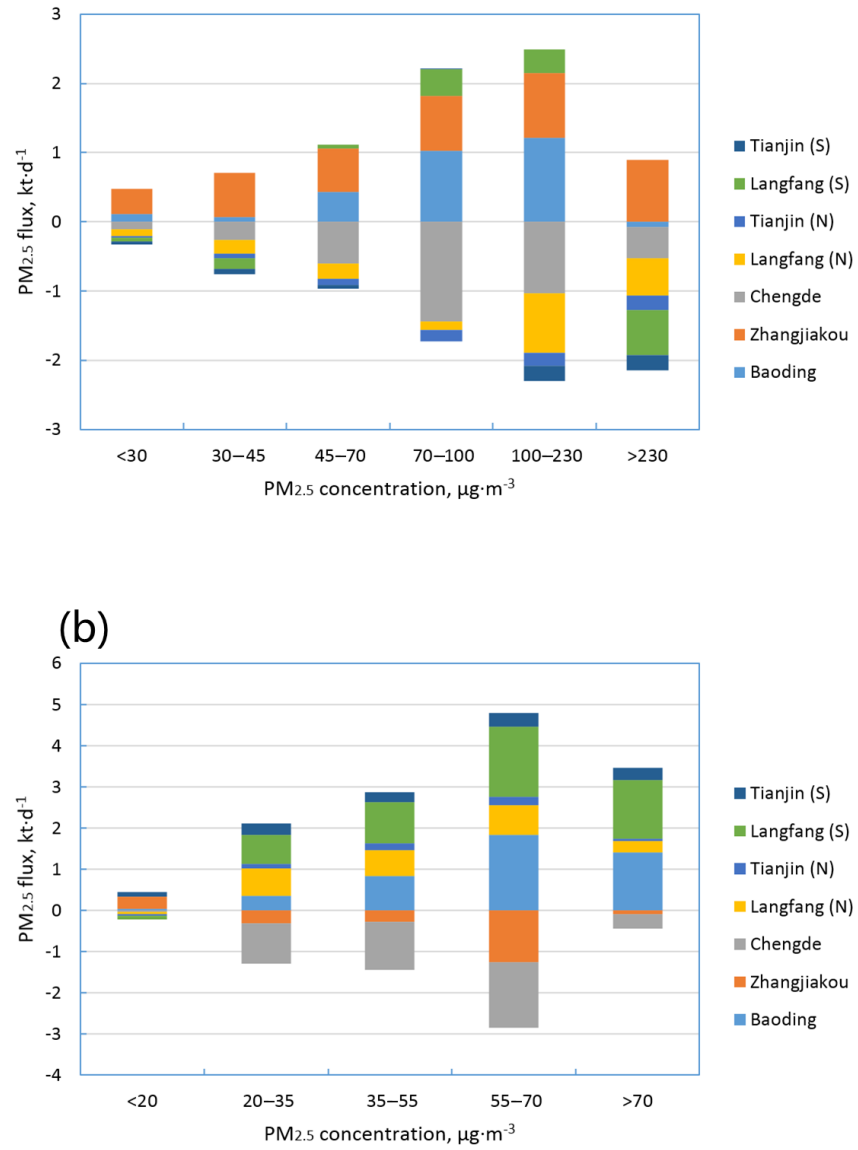

Figure 8. $\mathrm{PM}_{2.5}$ average flux in different degrees of pollution in (a) January and (b) July.

$60,80,90$ percentiles in July. The groups are denser at higher concentrations to better reveal the details around heavy pollution periods.

In January, the transport becomes stronger when the concentration is higher, but the transport flux also decreases when the concentration is the highest. The inflow from Baoding and outflow to Chengde, which are indicators of the southwest-northeast pathway, also rise gradually, followed by a sudden decrease. In July, the situation is similar, although the decrease is less significant. This result is consistent with Tang et al. (2015) and Zhu et al. (2016), who found that the southwest-northeast transport pathway is more significant when the pollution is still rising.

To reveal the daily characteristics comprehensively, we present the net $\mathrm{PM}_{2.5}$ fluxes of Beijing during two heavy pollution episodes in January and July of 2012 as examples. In January, we choose 17th-19th, which are the most polluted days in January (the simulated $\mathrm{PM}_{2.5}$ daily average concentrations all exceed $200 \mu \mathrm{g} \mathrm{m}^{-3}$ ). In July, we also choose the period with the highest concentration, i.e., 18th to 20th. The results are shown in Fig. 9.
The magnitude of net fluxes during the 17 and 18 January period $\left(-590\right.$ and $\left.688 \mathrm{tday}^{-1}\right)$ is much higher than the monthly average value $\left(139 \mathrm{tday}^{-1}\right)$. For 17 January, there are some weak outflows mainly to Langfang at lower levels, while stronger inflows from Baoding and Zhangjiakou occur at $300-600 \mathrm{~m}$. On 18 January, fluxes at lower levels remain relatively small though the inflow and outflow directions reverse. However, strong inputs from Baoding and Langfang at above $300 \mathrm{~m}$ become significantly stronger. It can be seen that although the fluxes near the ground are small, the inflow transport can be quite strong at levels above $300 \mathrm{~m}$. Coincidentally, the elevation of the mountains in the northwest of Beijing are commonly higher than $300 \mathrm{~m}$, making it harder for the inflowing $\mathrm{PM}_{2.5}$ to flow out. The large amount of $\mathrm{PM}_{2.5}$ inflows can only be efficiently blown out to the northeast direction (Chengde, Langfang $(\mathrm{N})$ and Tianjin $(\mathrm{N})$ ). These results are consistent with Jiang et al. (2015), who also found a strong southerly input at a high level during a haze episode in winter.

However, on 19 January when the concentration reaches its peak, the inflow transport becomes weaker than the previous days, especially for the southwest inflow. The $\mathrm{PM}_{2.5}$ experiences a significant inflow from the southwest followed by an accumulation period with little inflow. Therefore, the southwest-northeast pathway is of great importance during the first days of this heavy pollution period.

For the day with the highest concentration in July (20 July), the vertical distribution does not show much difference from the July average (Fig. 5f), except for the magnitude. The fluxes are about $1 / 5$ of the monthly average, or less than $1 / 10$ of that in the heavy pollution period in January. This result suggests that the heavy pollution in Beijing on 20 July is not dominated by inter-city transport on that particular day. However, the situation is completely different on 18 and 19 July (Fig. 7d, e), the days when the simulated $\mathrm{PM}_{2.5}$ concentration reaches a high level but is still rising in this pollution episode. The magnitude of fluxes is about 6 times larger than the monthly average, or some 30 times larger than on 20 July. More importantly, the outflow flux is much smaller than the inflow flux contributed mainly by Baoding and Langfang, which correspond to the southwest-northeast and southeast-northwest pathways respectively. Therefore, we can draw a conclusion about how the $\mathrm{PM}_{2.5}$ transport affects the air quality in Beijing during this pollution episode. On 18 July, the $\mathrm{PM}_{2.5}$ starts to flow into Beijing through the southeast-northwest and southwest-northeast pathways with a very strong flux, but very little flows out, causing an accumulative increase of the $\mathrm{PM}_{2.5}$ concentration. On 20 July, the wind field becomes stable and the transport weakens, but the $\mathrm{PM}_{2.5}$ that had flowed in before this point accumulates to form heavy pollution. This result indicates that both the southeast-northwest and the southwest-northeast pathway are important for Beijing during this polluted period, and emissions from outside Beijing should be controlled at least 2 days in advance to reduce the peak concentration. 
(a) Jan 17

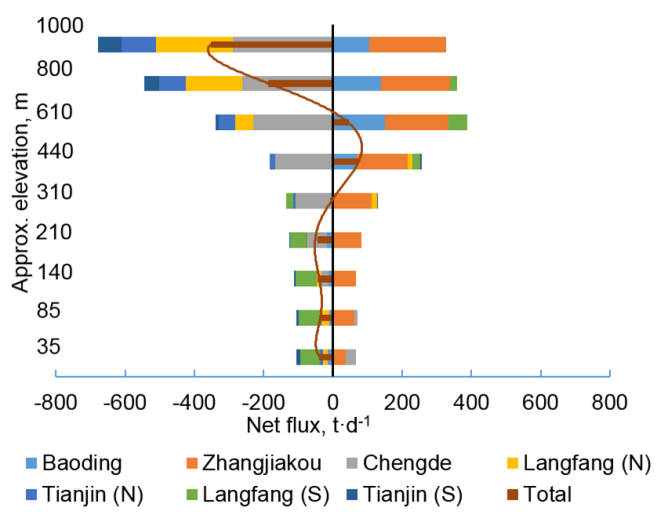

(b) Jan 18

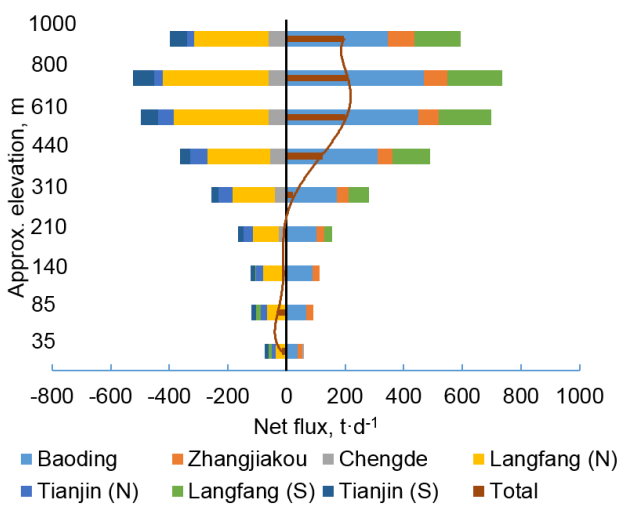

(c) Jan 19

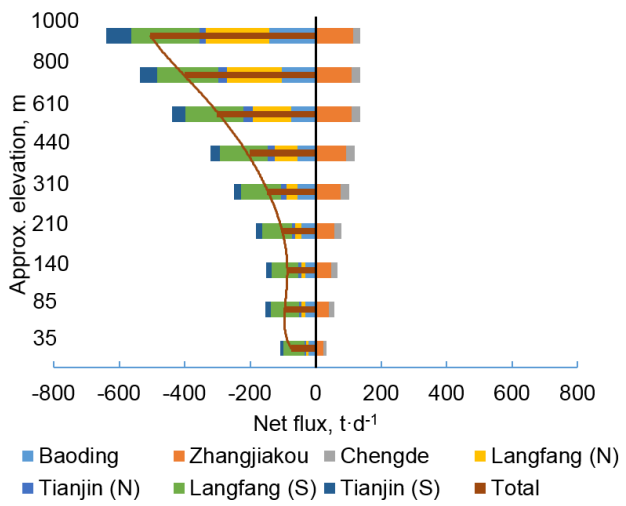

(d) Jul 18

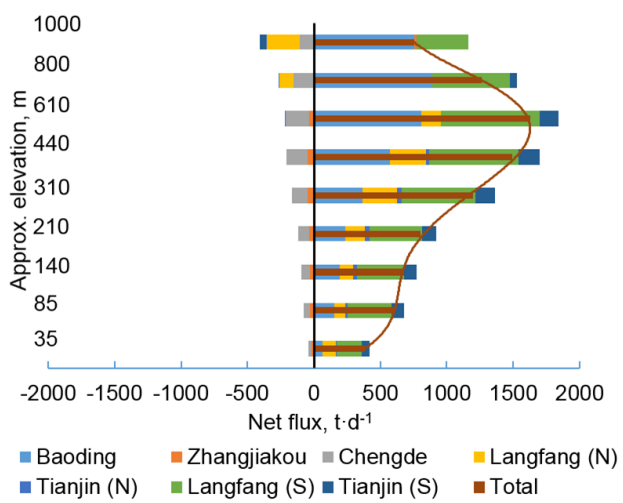

(e) Jul 19

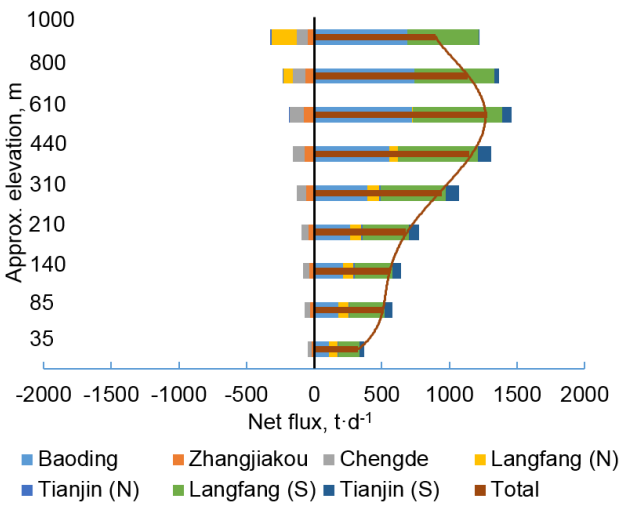

(f) Jul 20

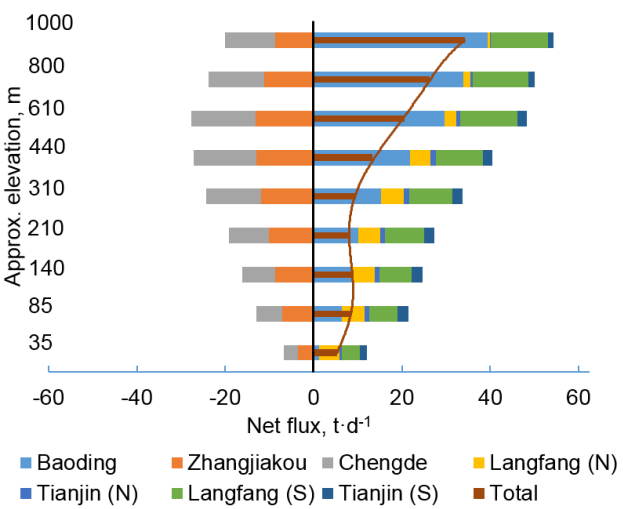

Figure 9. $\mathrm{PM}_{2.5}$ fluxes during heavy pollution days in Beijing in January and July: (a) 17 January, (b) 18 January, (c) 19 January, (d) 18 July, (e) 19 July and (f) 20 July.

From the discussions above, we can see that $\mathrm{PM}_{2.5}$ transport plays an important role in the heavy pollution periods in Beijing. We further analyze the $\mathrm{PM}_{2.5}$ flux data of the three cities day by day, and try to identify the presence of transport pathway for each day in Beijing, based on whether the inflow flux from a certain direction is significantly larger than the others. Finally, 8 days in January and 4 days in July are subject to the transport from the southwest-northeast path- way, 22 days in January are subject to the transport from the northwest-southeast pathway, and 8 days in July are subject to the transport from the southeast-northwest pathway. In July, there are 8 other days that are subject to both the southeast-northwest pathway and the southwest-northeast pathway ("SE-NW + SW-NE" for short). Moreover, some days do not show a clear transport direction, which are referred to as "unclassifiable days". We calculate the average 
Table 3. The mean and maximum simulated $\mathrm{PM}_{2.5}$ concentrations in Beijing for all days in January and July and for the days that belong to particular transport pathways.

\begin{tabular}{|c|c|c|c|c|}
\hline Month & Pathway type & Days & $\begin{array}{l}\text { Mean } \mathrm{PM}_{2.5} \text { conc. } \\
\text { in Beijing, } \mu \mathrm{g} \mathrm{m}^{-3}\end{array}$ & $\begin{array}{l}\text { Max } \mathrm{PM}_{2.5} \text { conc. } \\
\text { in Beijing, } \mu \mathrm{g} \mathrm{m}^{-3}\end{array}$ \\
\hline \multirow{4}{*}{ Jan } & All days & 31 & 65.2 & 270.7 \\
\hline & Southwest-northeast & 8 & 85.1 & 211.5 \\
\hline & Northwest-southeast & 22 & 58.6 & 270.7 \\
\hline & Unclassifiable day(s) & 1 & 53.0 & 53.0 \\
\hline \multirow{6}{*}{ Jul } & All days & 31 & 35.0 & 94.4 \\
\hline & Southwest-northeast & 4 & 54.2 & 94.4 \\
\hline & Northwest-southeast & 5 & 15.4 & 30.9 \\
\hline & Southeast-northwest & 8 & 29.4 & 53.2 \\
\hline & SW-NE + SE-NW & 8 & 47.4 & 71.0 \\
\hline & Unclassifiable day(s) & 9 & 29.3 & 79.7 \\
\hline
\end{tabular}

simulated concentration for each transport pathway. The results are shown in Table 3.

The days with southwest-northeast pathway transport show the highest $\mathrm{PM}_{2.5}$ average concentrations among all days in both January and July. Therefore, the southwestnortheast pathway should be the focus of control strategies. In contrast, the northwest-southeast pathway tends to coincide with the lowest concentrations in both seasons. Note that in January, the day with the highest concentration (19 January) is coincidentally identified as the northwest-southeast pathway. That day is on the eve of a rapid clearing by the northwest wind (Fig. 2a). While the cold front is passing, the heavy polluted air mass is forced to move from the northwest to southeast, which causes a significant transport. However, since the pollution brought by such transport usually coincides with a strong cold front, the $\mathrm{PM}_{2.5}$ concentration would most likely soon become very low (Jia et al., 2008). If we exclude 19 January from the northwest-southeast pathway days, the average concentration would only be $48.5 \mu \mathrm{g} \mathrm{m}^{-3}$.

In July, the southeast-northwest pathway and the southwest-northeast pathway happen simultaneously for 8 days. The average concentration is $47.4 \mu \mathrm{g} \mathrm{m}^{-3}$, the second highest in July, which further emphasizes the importance of the transport from the southwest. In summary, the southwestnortheast pathway should definitely be taken into consideration in both January and July, followed by the southeastnorthwest pathway in July.

Besides the daily variability of $\mathrm{PM}_{2.5}$ transport, we also analyzed the diurnal variability brought by the "mountain plain wind cycle" in summer in Beijing (Tang et al., 2016). However, because the average plain wind is much stronger than the mountain wind which is only obvious below $200 \mathrm{~m}$, the fluxes brought by the mountain wind is much weaker than that by plain wind (Fig. S6). The diurnal variation of winds does not have a significant influence on the direction of the transport fluxes.

\section{Conclusions}

By calculating $\mathrm{PM}_{2.5}$ inflow and outflow fluxes through the boundaries between each two prefecture-level cities, this study has shown the major $\mathrm{PM}_{2.5}$ input and output directions in winter and summer for Beijing, Tianjin and Shijiazhuang. For Beijing, the inflow fluxes mainly come from the northwest and southwest in winter, and the southeast and southwest in summer. For Tianjin, the inflow fluxes are mostly from the northwest and northeast in winter, and the east and northeast in summer. In Shijiazhuang, however, the four neighboring regions contribute a comparable amount of inflow fluxes in both winter and summer.

By analyzing the net $\mathrm{PM}_{2.5}$ fluxes and their vertical distribution, we identify several major transport pathways and the height at which they occur: the northwest-southeast pathway in winter (at all levels below $1000 \mathrm{~m}$, but stronger at levels above $300 \mathrm{~m}$ ), the southeast-northwest pathway in summer (at all levels below $1000 \mathrm{~m}$ ), and the southwest-northeast pathway in both winter and in summer (at levels between 300 and $1000 \mathrm{~m}$ ). Although the third pathway does not happen as frequently as the other two in corresponding seasons, it is accompanied by quite high $\mathrm{PM}_{2.5}$ concentrations in both seasons. Additionally, the relatively large transport height of this pathway suggests the importance of the long-range transport of $\mathrm{PM}_{2.5}$ on air quality. In winter especially, even if the wind speed near the ground is low, which we often refer to as "steady" conditions, the transport above $300 \mathrm{~m}$, which is primarily associated with long-range transport, could still be strong. These findings suggest that the joint control for cities on the southwest-northeast pathway should be emphasized in both winter and summer.

By analyzing daily transport fluxes in Beijing, we also find that the flux during days with higher $\mathrm{PM}_{2.5}$ concentration is generally higher, but the flux during the top $10 \%$ of polluted days is smaller. The flux during heavy pollution episodes is stronger than the monthly average for the two polluted peri- 
ods investigated in this study. In the heavy pollution episode in summer, $\mathrm{PM}_{2.5}$ flows into Beijing and accumulates for two days, leading to heavy pollution. Therefore, mitigating emissions from a larger area may be essential for the control of ambient $\mathrm{PM}_{2.5}$ in Beijing. Moreover, it appears important to control the upstream sources several days in advance to mitigate $\mathrm{PM}_{2.5}$ accumulations, rather than only taking actions when the pollution is already heavy. However, we must note that the two episodes we studied may not represent the general characteristics of heavy pollution episodes, which require a more systematic analysis in the future.

The current study has several limitations. First, we only quantify the transport of $\mathrm{PM}_{2.5}$ at the boundary of the city, which is not the only way by which transport process may influence the $\mathrm{PM}_{2.5}$ concentration in the target city. Other processes include the inter-city transport of gaseous precursors that remain in the gaseous phase at the boundary but may convert to secondary $\mathrm{PM}_{2.5}$ in the target city. Secondly, the $\mathrm{PM}_{2.5}$ transported through the outer boundary is a mixture of different sources and does not just stem from the neighbor city. Although we have established a general transport feature for the BTH region which can facilitate a qualitative understanding of where the fluxes are mainly from, the flux approach cannot quantitatively evaluate the contribution from each city in the upstream areas. If we want to overcome these disadvantages, a lifetime tracing during the emission, transportation, reaction and deposition processes of $\mathrm{PM}_{2.5}$ and its gaseous precursors is needed. Therefore, future studies may combine the flux calculation with the tagging models to overcome these issues. Despite these limitations, the flux approach has indeed proved to be a powerful tool to visually assess the inter-city transport of pollutants.

Data availability. All data needed to evaluate the conclusion of this paper are provided in the main text and in the Supplement. Other relevant data are available upon request.

\section{The Supplement related to this article is available online} at https://doi.org/10.5194/acp-18-4843-2018-supplement.

Competing interests. The authors declare that they have no conflict of interest.

Special issue statement. This article is part of the special issue "Regional transport and transformation of air pollution in eastern China". It is not associated with a conference.
Acknowledgements. We hereby express our gratitude to Yangjun Wang from Shanghai University, Jia Xing from Tsinghua University and Jiandong Wang from Max Planck Institute who helped us set up the modeling system and gave us useful suggestions.

This research has been supported by National Science Foundation of China (21625701 \& 21521064). The simulations were completed on the "Explorer 100" cluster system of Tsinghua National Laboratory for Information Science and Technology.

Edited by: Jianmin Chen

Reviewed by: two anonymous referees

\section{References}

An, J., Li, J., Zhang, W., Chen, Y., Qu, Y., and Xiang, W.: Simulation of transboundary transport fluxes of air pollutants among Beijing, Tianjin, and Hebei Province of China, Acta Scientiae Circumstantiae, 32, 2684-2692, 2012.

An, X., Zhu, T., Wang, Z., Li, C., and Wang, Y.: A modeling analysis of a heavy air pollution episode occurred in Beijing, Atmos. Chem. Phys., 7, 3103-3114, https://doi.org/10.5194/acp-7-31032007, 2007.

Berge, E. and Jakobsen, H. A.: A regional scale multi-layer model for the calculation of long-term transport and deposition of air pollution in Europe, Tellus B, 50, 205-223, 10.1034/j.16000889.1998.t01-2-00001.x, 1998.

BJEPB: Preliminary study of the atmospheric environment protection strategy in The 12th Five-year Plan, Beijing, China, 44-56, 2010 .

BJEPB: Beijing Environmental Statement 2014, available at: http://www.bjepb.gov.cn/2014zt_jsxl/index.html (last access: 30 November 2016), 2015.

Boylan, J. W. and Russell, A. G.: PM and light extinction model performance metrics, goals, and criteria for threedimensional air quality models, Atmos. Environ., 40, 49464959, https://doi.org/10.1016/j.atmosenv.2005.09.087, 2006.

Cai, S., Wang, Y., Zhao, B., Wang, S., Chang, X., and Hao, J.: The impact of the "Air Pollution Prevention and Control Action Plan" on $\mathrm{PM}_{2.5}$ concentrations in Jing-Jin-Ji region during 2012-2020, Sci. Total Environ., 580, 197-209, https://doi.org/10.1016/j.scitotenv.2016.11.188, 2017.

Emery, C., Tai, E., and Yarwood, G.: Enhanced meteorological modeling and performance evaluation for two texas episodes, Prepared for the Texas Natural Resource Conservation Commission, by ENVIRON International Corp, Novato, CA, 2001.

Fu, X., Wang, S., Zhao, B., Xing, J., Cheng, Z., Liu, H., and Hao, J.: Emission inventory of primary pollutants and chemical speciation in 2010 for the Yangtze River Delta region, China, Atmos. Environ., 70, 39-50, https://doi.org/10.1016/j.atmosenv.2012.12.034, 2013.

Fu, X., Wang, S., Chang, X., Cai, S., Xing, J., and Hao, J.: Modeling analysis of secondary inorganic aerosols over China: pollution characteristics, and meteorological and dust impacts, Sci. Rep.UK, 6, 35992, https://doi.org/10.1038/srep35992, 2016.

Heald, C. L., Jacob, D. J., Park, R. J., Russell, L. M., Huebert, B. J., Seinfeld, J. H., Liao, H., and Weber, R. J.: A large organic aerosol source in the free troposphere miss- 
ing from current models, Geophys. Res. Lett., 32, L18809, https://doi.org/10.1029/2005g1023831, 2005.

Holton, J. R. and Hakim, G. J.: An introduction to dynamic meteorology, 5th Edn., Elsevier, MA, USA, 532 pp., 2012.

In, H.-J., Byun, D. W., Park, R. J., Moon, N.-K., Kim, S., and Zhong, S.: Impact of transboundary transport of carbonaceous aerosols on the regional air quality in the United States: A case study of the South American wildland fire of May 1998, J. Geophys. Res.-Atmos., 112, D07201, https://doi.org/10.1029/2006jd007544, 2007.

Itahashi, S., Uno, I., and Kim, S.: Source Contributions of Sulfate Aerosol over East Asia Estimated by CMAQ-DDM, Environ. Sci. Technol., 46, 6733-6741, https://doi.org/10.1021/es300887w, 2012.

Jenner, S. L. and Abiodun, B. J.: The transport of atmospheric sulfur over Cape Town, Atmos. Environ., 79, 248-260, https://doi.org/10.1016/j.atmosenv.2013.06.010, 2013.

Jia, Y., Rahn, K. A., He, K., Wen, T., and Wang, Y.: A novel technique for quantifying the regional component of urban aerosol solely from its sawtooth cycles, J. Geophys. Res.-Atmos., 113, D21309, https://doi.org/10.1029/2008jd010389, 2008.

Jiang, C., Wang, H., Zhao, T., Li, T., and Che, H.: Modeling study of $\mathrm{PM}_{2.5}$ pollutant transport across cities in China's Jing-JinJi region during a severe haze episode in December 2013, Atmos. Chem. Phys., 15, 5803-5814, https://doi.org/10.5194/acp15-5803-2015, 2015.

Kwok, R. H. F., Baker, K. R., Napelenok, S. L., and Tonnesen, G. S.: Photochemical grid model implementation and application of VOC, $\mathrm{NO}_{x}$, and $\mathrm{O}_{3}$ source apportionment, Geosci. Model Dev., 8, 99-114, https://doi.org/10.5194/gmd-8-99-2015, 2015.

Li, M., Zhang, Q., Kurokawa, J.-I., Woo, J.-H., He, K., Lu, Z., Ohara, T., Song, Y., Streets, D. G., Carmichael, G. R., Cheng, Y., Hong, C., Huo, H., Jiang, X., Kang, S., Liu, F., Su, H., and Zheng, B.: MIX: a mosaic Asian anthropogenic emission inventory under the international collaboration framework of the MICS-Asia and HTAP, Atmos. Chem. Phys., 17, 935-963, https://doi.org/10.5194/acp-17-935-2017, 2017.

Liu, J., Mauzerall, D. L., Chen, Q., Zhang, Q., Song, Y., Peng, W., Klimont, Z., Qiu, X., Zhang, S., Hu, M., Lin, W., Smith, K. R., and Zhu, T.: Air pollutant emissions from Chinese households: A major and underappreciated ambient pollution source, P. Natl. Acad. Sci. USA, 113, 7756-7761, 10.1073/pnas.1604537113, 2016

Mu, Q. and Zhang, S.-Q.: An evaluation of the economic loss due to the heavy haze during January 2013 in China, China Environmental Science, 33, 2087-2094, 2013.

Shi, C., Yao, Y., Zhang, P., and Qiu, M.: Transport Trajectory Classifying of $\mathrm{PM}_{10}$ in Hefei, Plateau Meteorology, 27, 1383-1391, 2008.

Simon, H. and Bhave, P. V.: Simulating the Degree of Oxidation in Atmospheric Organic Particles, Environ. Sci. Technol., 46, 331339, https://doi.org/10.1021/es202361w, 2012.

Stein, A. F., Draxler, R. R., Rolph, G. D., Stunder, B. J. B., Cohen, M. D., and Ngan, F.: NOAA'S HYSPLIT atmospheric transport and dispersion modeling System, B. Am. Meteorol. Soc., 96, 2059-2077, https://doi.org/10.1175/bams-d-14-00110.1, 2015.

Streets, D. G., Fu, J. S., Jang, C. J., Hao, J., He, K., Tang, X., Zhang, Y., Wang, Z., Li, Z., Zhang, Q., Wang, L., Wang, B., and Yu, C.: Air quality during the 2008
Beijing Olympic Games, Atmos. Environ., 41, 480-492, https://doi.org/10.1016/j.atmosenv.2006.08.046, 2007.

Tang, G., Zhu, X., Hu, B., Xin, J., Wang, L., Münkel, C., Mao, G., and Wang, Y.: Impact of emission controls on air quality in Beijing during APEC 2014: lidar ceilometer observations, Atmos. Chem. Phys., 15, 12667-12680, https://doi.org/10.5194/acp-1512667-2015, 2015.

Tang, G., Zhang, J., Zhu, X., Song, T., Münkel, C., Hu, B., Schäfer, K., Liu, Z., Zhang, J., Wang, L., Xin, J., Suppan, P., and Wang, Y.: Mixing layer height and its implications for air pollution over Beijing, China, Atmos. Chem. Phys., 16, 2459-2475, https://doi.org/10.5194/acp-16-2459-2016, 2016.

Wang, G., Zhang, R., Gomez, M. E., Yang, L., Zamora, M. L., Hu, M., Lin, Y., Peng, J., Guo, S., Meng, J., Li, J., Cheng, C., Hu, T., Ren, Y., Wang, Y., Gao, J., Cao, J., An, Z., Zhou, W., Li, G., Wang, J., Tian, P., Marrero-Ortiz, W., Secrest, J., Du, Z., Zheng, J., Shang, D., Zeng, L., Shao, M., Wang, W., Huang, Y., Wang, Y., Zhu, Y., Li, Y., Hu, J., Pan, B., Cai, L., Cheng, Y., Ji, Y., Zhang, F., Rosenfeld, D., Liss, P. S., Duce, R. A., Kolb, C. E., and Molina, M. J.: Persistent sulfate formation from London Fog to Chinese haze, P. Natl. Acad. Sci. USA, 113, 13630-13635, https://doi.org/10.1073/pnas.1616540113, 2016.

Wang, K., Zhang, Y., Jang, C., Phillips, S., and Wang, B.: Modeling intercontinental air pollution transport over the trans-Pacific region in 2001 using the Community Multiscale Air Quality modeling system, J. Geophys. Res.-Atmos., 114, D04307, https://doi.org/10.1029/2008jd010807, 2009.

Wang, L., Wei, Z., Wei, W., Fu, J. S., Meng, C., and Ma, S.: Source apportionment of $\mathrm{PM}_{2.5}$ in top polluted cities in Hebei, China using the CMAQ model, Atmos. Environ., 122, 723-736, https://doi.org/10.1016/j.atmosenv.2015.10.041, 2015.

Wang, L. T., Wei, Z., Yang, J., Zhang, Y., Zhang, F. F., Su, J., Meng, C. C., and Zhang, Q.: The 2013 severe haze over southern Hebei, China: model evaluation, source apportionment, and policy implications, Atmos. Chem. Phys., 14, 3151-3173, https://doi.org/10.5194/acp-14-3151-2014, 2014.

Wang, S., Xing, J., Chatani, S., Hao, J., Klimont, Z., Cofala, J., and Amann, M.: Verification of anthropogenic emissions of China by satellite and ground observations, Atmos. Environ., 45, 63476358, https://doi.org/10.1016/j.atmosenv.2011.08.054, 2011.

Wang, S. X., Zhao, B., Cai, S. Y., Klimont, Z., Nielsen, C. P., Morikawa, T., Woo, J. H., Kim, Y., Fu, X., Xu, J. Y., Hao, J. M., and He, K. B.: Emission trends and mitigation options for air pollutants in East Asia, Atmos. Chem. Phys., 14, 6571-6603, https://doi.org/10.5194/acp-14-6571-2014, 2014.

Wang, W., Wang, Z., Wu, Q., Gbaguidi, A., Zhang, W., Yan, P., and Yang, T.: Variation of $\mathrm{PM}_{10}$ Flux and Scenario Analysis before and after the Olympic Opening Ceremony in Beijing, Climatic and Environmental Research, 15, 652-661, 2010.

Wang, Z., Li, J., Wang, Z., Yang, W., Tang, X., Ge, B., Yan, P., Zhu, L., Chen, X., Chen, H., Wand, W., Li, J., Liu, B., Wang, X., Wand, W., Zhao, Y., Lu, N., and Su, D.: Modeling study of regional severe hazes over mid-eastern China in January 2013 and its implications on pollution prevention and control, Sci. China Earth-Sci., 57, 3-13, https://doi.org/10.1007/s11430-013-4793$0,2014$.

Wu, P., Ding, Y., and Liu, Y.: Atmospheric circulation and dynamic mechanism for persistent haze events in the 
Beijing-Tianjin-Hebei region, Adv. Atmos. Sci., 34, 429440, https://doi.org/10.1007/s00376-016-6158-z, 2017.

Zhang, Y., Ma, G., Yu, F., and Cao, D.: Health damage assessment due to $\mathrm{PM}_{2.5}$ exposure during haze pollution events in BeijingTianjin-Hebei region in January 2013, National Medical Journal of China, 93, 2707-2710, 2013.

Zhao, B., Xu, J., and Hao, J.: Impact of energy structure adjustment on air quality: a case study in Beijing, China, Front. Environ. Sci. En., 5, 378-390, https://doi.org/10.1007/s11783-011-0357$8,2011$.

Zhao, B., Wang, S., Wang, J., Fu, J. S., Liu, T., Xu, J., Fu, X., and Hao, J.: Impact of national $\mathrm{NO}_{x}$ and $\mathrm{SO}_{2}$ control policies on particulate matter pollution in China, Atmos. Environ., 77, 453463, https://doi.org/10.1016/j.atmosenv.2013.05.012, 2013a.

Zhao, B., Wang, S. X., Liu, H., Xu, J. Y., Fu, K., Klimont, Z., Hao, J. M., He, K. B., Cofala, J., and Amann, M.: NO$x$ emissions in China: historical trends and future perspectives, Atmos. Chem. Phys., 13, 9869-9897, https://doi.org/10.5194/acp13-9869-2013, 2013b.

Zhao, B., Wang, S. X., Xing, J., Fu, K., Fu, J. S., Jang, C., Zhu, Y., Dong, X. Y., Gao, Y., Wu, W. J., Wang, J. D., and Hao, J. M.: Assessing the nonlinear response of fine particles to precursor emissions: development and application of an extended response surface modeling technique v1.0, Geosci. Model Dev., 8, 115128, https://doi.org/10.5194/gmd-8-115-2015, 2015.
Zhao, B., Wang, S., Donahue, N. M., Jathar, S. H., Huang, X., Wu, W., Hao, J., and Robinson, A. L.: Quantifying the effect of organic aerosol aging and intermediate-volatility emissions on regional-scale aerosol pollution in China, Sci. Rep.-UK, 6, 28815, https://doi.org/10.1038/srep28815, 2016.

Zhao, B., Wu, W., Wang, S., Xing, J., Chang, X., Liou, K.-N., Jiang, J. H., Gu, Y., Jang, C., Fu, J. S., Zhu, Y., Wang, J., Lin, Y., and Hao, J.: A modeling study of the nonlinear response of fine particles to air pollutant emissions in the BeijingTianjin-Hebei region, Atmos. Chem. Phys., 17, 12031-12050, https://doi.org/10.5194/acp-17-12031-2017, 2017.

Zhao, P., Zhang, X., Xu, X., and Zhao, X.: Long-term visibility trends and characteristics in the region of Beijing, Tianjin, and Hebei, China, Atmos. Res., 101, 711-718, https://doi.org/10.1016/j.atmosres.2011.04.019, 2011.

Zhao, Y., Wang, S., Duan, L., Lei, Y., Cao, P., and Hao, J.: Primary air pollutant emissions of coal-fired power plants in China: Current status and future prediction, Atmos. Environ., 42, 84428452, https://doi.org/10.1016/j.atmosenv.2008.08.021, 2008.

Zhu, X., Tang, G., Hu, B., Wang, L., Xin, J., Zhang, J., Liu, Z., Muenkel, C., and Wang, Y.: Regional pollution and its formation mechanism over North China Plain: A case study with ceilometer observations and model simulations, J. Geophys. Res.-Atmos., 121, 14574-14588, https://doi.org/10.1002/2016jd025730, 2016. 